\title{
O Sonho de Ka
}

\author{
Aurora F. Bernardini
}

Na língua estão escondidas muitas verdades, diz V.V. Khlébnikov, um dos grandes poetas-filósofos de nosso século. Sua riquíssima obra é toda ela a busca dessas verdades. Os procedimentos são os mais variados

- desde a procura das motivações dos signos através de etimologias, analogias, associações, coincidências, até uma verdadeira geometria das letras e dos sons do alfabeto, com o que, por meio do cálculo de certas periodicidades (fora estudante de matemática), chega a descobertas e profecias surpreendentes.

Em português, a não ser alguns de seus poemas admiravelmente traduzidos por Augusto e Haroldo de Campos e Boris Schnaiderman em

Poesia Russa Moderna (Editora Civilização Brasileira S.A., Rio, 1968), pouco se conhece dele.

Gostaríamos de tornar conhecida também uma amostra de sua prosa, pela tradução de um dos capítulos de seu extraordinário conto "Ka", do qual comentamos a descrição de um sonho, tentando mostrar como os processos da linguagem coincidem com aqueles de nossa realidade mais profunda.

$\mathrm{Ka}$

Velimir Khlébnikov

(capitulo VI)

"Ponto de exclamação, sinal de pergunta, reticências. Lá, de onde sopra o vento dos deuses (1) e a deusa Isanagui (2) ei-la com seu tecido serpentino meio-prata, cinéreo (3). Para compreendê-lo, é preciso saber, que traços cinzaprata, quase pretos, alternam-se com outros transparentes, como uma janela ou um tinteiro. $\mathrm{O}$ encanto desta tela concebe-se apenas quando ela se ilumina da tênue luz da mão álacre-jovem. Então sobre as ondas de seda prateada corre um matiz de fogo e desaparece de novo, fuste de palmeira ${ }^{(4)}$. Assim trepida o incêndio da tarde sobre os edifícios da cidade. Grandes olhos fascinantes. Chamase a si própria adorável, fascinante". - Não é isso, - interrompi a torrente de palavras: - você se engana, — observei severo. — "Será?" — respondeu $\mathrm{Ka}$ fingindo tristeza. 
- "Imagine, - voltou a dizer, ainda mais alegre, um pouco mais tarde, como se me trouxesse uma notícia grata: - Três erros: 1) na cidade, 2) na rua, 3) em casa. Mas onde? - Não sei", — respondeu Ka: a candura ressoava em sua voz. Embora eu o amasse muito, brigamos. Teve que se afastar. Agitando as assas, vestido de cinza, sumiu. A penumbra tremia-lhe aos pés, ele era como que um noviço ${ }^{(5)}$ aos saltos, meu altivo e maravilhoso vagabundo. "Ah, é ele, o olhos-de-abismo! - exclamaram alguns transeuntes: - mas, Tamara onde está, onde está Gudal?" (6) — dando assim pretexto, cidadãos assustados, para embutir na novela estas miudezas artísticas. Enquanto isso eu andava pela praia de um canto a outro, e o vento arrancava minha cartola e atirava gotas oblíquas no rosto e no pano preto. Acompanhei com os olhos a nuvemzinha dourando-se e estalei os dedos.

Eu sabia que Ka estava ofendido.

Uma vez mais ele apareceu ao longe, agitando de raro em raro suas asas. E senti que era um cantor solitário e que a Harpa de Sangue estava em minhas mãos. Eu era pastor; tinha rebanhos de almas. Agora não mais. Nesse ínterim alguém seco-enrugado aproximou-se de mim. Espiou ao redor, lançou um olhar significativo e tendo dito: "será! em breve!", acenou com a cabeça e desapareceu. Fui atrás dele. Lá, um bosque. Os melros pretos e as branquetas ${ }^{(7)}$ de cabeça preta saltitavam na folhagem. Qual roucos bois de estepe, as esplêndidas garças cinzas, rugiam e mugiam, os bicos estendidos para o céu, sobre o galho mais alto do velho carvalho seco. Mas eis que aparece o noviço, entre os carvalhos. todo preto, com o alto chapéu seco - amarrotado. Um rosto de bílis, enrugado. O carvalho tinha um ôco, nele havia imagens e velas. Não tinha casca, pois há muito tempo fora mascada por doentes de dor-de-dente. No bosque, uma penumbra eterna. Besouros-corças corriam pela casca dos carvalhos e, entrando em combate singular, furavam as asas um ao outro, e entre os chifres negros de um vivo podia-se encontrar a cabeça seca de um morto. Bêbados de suco de carvalho, caiam em poder dos meninos. Adormeci aqui, e a melhor novela dos arameus "Leili e Medlum" visitou ainda uma vez o sono do fatigado mortal.

Voltava para casa e passava em meio do velofino rebanho das pessoas. Chegou à cidade uma exposição de raridades, e lá vi um macaco empalhado ${ }^{(8)}$ com espuma nos lábios negros, de cera; a costura preta claramente visível sobre o peito; nos braços uma mulher de cera. Fui embora.

A queda das corujas, corujincidência, estranha e enigmática, surpreendeu-me. Creio que diante de uma guerra muito grande a palavra "adusto" possui um particular sentido assustador, tal como a guerra ainda a todos insuspeita, esconder-se-á feito um conjurado, feito uma cotovia prematura, nesta palavra, aparentada com a raiz de susto.

Mas a mim no meio destas sarças de amora, no meio desses salgueiros, cobertos de raízes de ruivos cabelos espessos, onde tudo era tranqüilo-nublado, austero-cinza, onde o beberrão solitário se agitava no ar e as árvores eram calmas e severas, uma implorante erva empoeirada, se me enroscava nas pernas e serpenteava pelo chão, pecadora que pedia misericórdia. Arranquei seus fios com meus passos rudes, olhei para ela e disse:

"E o passo brutal tornar-se-á mais forte, para rasgar o negro solanum (9) que implora". 
Eu ia para casa; lá já esperavam minha aventura e sabiam dela; cobrindo os olhos com a mão, as pessoas vinham a meu encontro. De meu braço pendia, enrolada com graça, uma pequena víbora domesticada ${ }^{(10)}$. Eu a amava. morta" (11)

- "Agi como um corvo, - pensei: — no começo, água viva, depois, água

E daí, não darei uma segunda vez!

\section{Notas}

1. De onde sopra o vento dos deuses: referência a um trecho de "Svóiasi", obra de Khlébnikov onde ele esboça uma sua famosa teoria:

"Quando percebi que as velhas linhas de repente empalideciam, e o futuro nelas oculto se transformava no dia de hoje, compreendi que a pátria da criação está situada no futuro. E dele que sopra o vento dos deuses da palavra". (tradução de Boris Schnaiderman, retirada de "Uma visão dialética e radical da Literatura" - em "Linguística Poética - Cinema”. Ed. Perspectiva - São Paulo, 1970.

2. Isanágui: Deus do ar, japonês, relaciona-se com Chu Chu - deus do ar na mitologia egípcia, cujo sopro é necessário à palavra.

Quando o tribunal de Osiris condenava Bha, (a alma), a magia dos sacerdotes tinha um recurso. Pode parecer estranho, mas os deuses do Egito podiam ser enganados, ameaçados e ridicularizados. Os egípcios tinham tamanha confiança no poder das palavras rituais e dos gestos mágicos, que acreditavam ser possível dobrar os deuses à sua vontade. Os sacerdotes cobriam com fórmulas mágicas os rolos de papiros que davam ao defunto a possibilidade de enfrentar seus juizes, no além.

O Livro dos Mortos descrevia com precisão os obstáculos que encontraria a alma em sua viagem para o reino das sombras e explicava como o morto poderia perorar sua causa. Um dos rolos continha os nomes secretos dos demônios e dos deuses inquisidores, pois o conhecimento do verdadeiro nome de um espírito dava ao defunto todo poder sobre ele. As respostas às perguntas eram transcritas, palavra por palavra e era suficiente conhecê-las para obter um veredito favorável.

3. Ei-la com seu tecido serpentino, meio-prata, cinéreo: trata-se de uma retomada do motivo da exposição de quadros que Khlébnikov visitou e que o impressionou particularmente. Eis um trecho de suas impressões no fragmento "Um Sonho" traduzido em La Pieu du Futur (Éditions L'age d'homme, Paris, 1967): “... Nous nous trouvions devant une peinture... Nous discutions tres haut et avec animation, mais un gardien de moeurs vint se joindre à nous et fit remarquer tout l'inacceptable d'une toile: à son avis, auquel nous ne pouvions que souscrire telle était, il me semble, une turque couché au bord de la mer.

Seul son front et un coin de la bouche étaient voilés par un bandeau noir orné de dentelles; l'ombre couvrait la bouche et le menton. Des 
taches d'or alternaient avec les ombres bleues de ce corps pris dans les mailles des rayons du midi."

4. Espique: do russo literal: fuste de palmeira.

5. Noviço: do russo: monge; aqui se presta melhor o sentido de noviço.

6. Tamara e Gudal: Tamara, filha do príncipe georgiano Gudal e heroina do poema de Lérmontov "O Demônio", foi amada pelo príncipe das trevas.

7. Branquetas: do russo slafka. É freqüente o emprego desta palavra por Khlébnikov.

8. Macaco empalhado: sem dúvida, a imagem do macaco (ou gorila), como animal selvagem, vivo ou empalhado, pela frequiência com que ocorre em seus textos, deve provir de um "motivo concreto" que impressionou fortemente Khlébnikov. Cf. como (na versão do monstro com uma mulher nos braços, que surge também em Ka) ele é tratado na poesia "o monstro" (p. 61 de Choix de Poèmes. P. J. Oswald, Paris, 1967).

9. Solanum: trata-se de uma erva das espécies Solanum Dulcamara ou Solanum Nigrum.

10. Pequena víbora doméstica: de acordo com a informação pessoal de $\mathrm{R}$. Duganov, crítico literário soviético, estudioso de Khlébnikov, Nadiejda V. Nikoláieva possuia, na época em que o autor a conheceu, uma pequena serpente domesticada que costumava enrolar-se em seu braço.

11. No começo dei água viva, depois morta: nos contos de fada russos, a água morta cola um corpo decepado, mas só a água viva ressuscita.

Tradução e notas de Aurora F. Bernardini, discutidas com Boris Schnaiderman e Haroldo de Campos.

\section{O Sonho de Ka}

A narrativa de $\mathbf{K a}{ }^{(1)}$ desenrola-se ao longo de marcos significativos, cujos campos de força se entrecruzam durante o conto inteiro. As palavras, como quer Khlébnikov ${ }^{(2)}$, vivem uma dupla vida ora o som é todo-poderoso e autônomo, e então a parte racional da palavra suscitada pelo nome conserva-se na sombra - ora o som cessa de ser soberano, torna-se nome e passa a servir à razão.

"Não é difícil notar que a estação do ressoamento verbal é o momento nupcial da língua, a época das palavras noivas, e que a estação das palavras saturadas de razão... é a estação da abundância outonal, o tempo da família e das crianças..."

Quando porém as palavras-sons, ao surgirem, aparecem como fórmulas, encantações, evocações obscuras de um longínquo passado, elas concentram em si o máximo de energia: ultrapassam a razão e apelam diretamente para o crepúsculo da alma - o mundo dos sentidos e dos sentimentos.

Assim, diante do leitor, não totalmente ignaro, surge $\mathrm{Ka}$ - a sombra da alma. 
A consoante $\mathbf{k}$, segundo Khlébnikov ${ }^{(3)}$, significa ausência de movimento, o repouso de uma rede de $\mathbf{n}$ pontos e a conservação, por parte deles, de sua posição mútua - o fim do movimento, Em Ka, a consoante inicial rege o resto da palavra, constituída de uma única outra letra, a vogal a, começo do alfabeto e começo, talvez, em geral. Ka é o ponto básico que rege a rede dos pontos móveis do conto.

Pelas notas que ilustram a tradução, informações extra-textuais sem as quais o estabelecimento da isotopia narrativa seria impossível, notamos que há uma série de generalizações que podem ser feitas em volta do emblema Ka ${ }^{(4)}$. Entretanto, pela leitura dos próprios trabalhos de Khlébnikov, bem como por considerações feitas em análises empreendidas por estudiosos do poeta (especialmente V. Vs. Ivanov e R. Duganov) ${ }^{(5)}$, podemos licitamente supor que várias generalizações de Khlébnikov tenham nascido de premissas de ordem concreta e até mesmo figurativa.

A apreensão do elemento concreto seria, na psicologia da criação de Khlébnikov, um dos estímulos desencadeadores do processo imagético. $\mathrm{O}$ elemento ao redor do qual ele teceria sua rede de impressões.

À primeira vista parece apenas curiosa coincidência o fato que o maior número de 'motivos concretos' de que tomamos conhecimento e que comparecem no conto Ka se concentre justamente no capítulo sexto ${ }^{(6)}$. Eis a relação dos mais imediatos:

1. lá de onde sopra o vento dos deuses...

(retomada de um motivo caro a Khlébnikov — vide nota à tradução).
2. ela está com seu tecido serpentino...

(retomada de um tema relacionado com uma exposição de quadros visitada pelo poeta — vide nota à tradução).

3. olhos - palavra-motivo recorrente em "Ka".

4. Tamara e Gudal - vide nota à tradução.

5. Leili e Medlum - retomada da figura dos amantes eternos que são um dos temas constantes do conto.

6. harpa de sangue - figura que provavelmente se prende a algum 'motivo concreto' da experiência do autor.

7. rebanho - retomada de outra palavra-chave da obra.

8. garça - idem.

9. velofino rebanho de pessoas $-\mathrm{ibi}-$ dem.

10. exposição de raridades — referência a um episódio da vida real do autor.

11. macaco empalhado - idem (vide nota à tradução)

12. mulher de cera - idem, ibidem.

13. queda das corujas - ocorrência, talvez forjada, da qual se vale Khlébnikov para um surpreendente jogo de palavras.

14. pequena víbora doméstica — vide nota à tradução.

15. aqui como um corvo. . . no começo, água viva, depois, água morta idem.

O que parecia coincidência, entretanto, explica-se quando percebemos que no capítulo sexto tudo converge para o sonho do "fatigado mortal".

É verdade que poderíamos encontrar em cada capítulo de Ka uma ou mais 
partes semelhantes a pedaços de sonho

- "traços cinza-prata, quase pretos que se alternam com outros transparentes como uma janela ou um tinteiro", o próprio Khlébnikov explicita, ao apresentar Ka: "ele vai de sonho em sonho, atravessa o tempo e atinge os bronzes (os bronzes dos tempos)" - contudo, é neste capítulo que ele se refere diretamente a um trecho de sua obra como a um sonho e o descreve como tal.

Freud, em sua obra "O delírio e os sonhos em 'A Gradiva' de W. Jensen" (in Obras Completas - Volumen I op. cit.) aplica o procedimento da psicoterapia justamente aos sonhos e ao delírio que o autor do livro descreve como tais. O resultado é dos mais satisfatórios: os 'sonhos' descritos na obra literária não se diferenciam dos sonhos que ocorrem na vida real.

Se aplicarmos ao sonho descrito ne sexto capítulo de Ka a teoria que Freud aplica em sua Interpretação dos sonhos a um seu próprio sonho e se acompanharmos as etapas, passo a passo, nós também verificaremos coincidências surpreendentes, não só entre um sonho da vida real( o de Freud), e um sonho-obra literária (o do narrador de Ka), mas encontraremos correspondências estritas entre algumas etapas fundamentais da elaboração onírica (transformação do conteúdo latente em manifesto) e o procedimento da elaboração poética de nosso autor.

Apesar da possibilidade atraente de lançarmos pontes entre os conteúdos manifestos no sonho e os 'motivos concretos' que teriam impressionado Khlébnikov na vida real e conjeturarmos a respeito dos caminhos e supradeterminações das idéias latentes, com a finalidade de descobrir o significado do sonho, resistimos em tempo à tentação. Nos seria indispensável, para tanto, o conhecimento exaustivo do contexto da vida do autor, sem contar o domínio da técnica preconizada por Freud.
Empenhar-nos-emos aqui em focalizar apenas os pontos de correspondência entre os dois procedimentos aos quais nos referimos acima.

Damos aqui, a título de documentação e para que se saiba em que exato contexto serão tomados os termos que vamos empregar, o apanhado da Interpretação dos sonhos (op. cit.) de Freud, onde salientamos os pontos mais significativos que podem ser aplicados ao processo da elaboração poética.

Freud aplica ao sonho o procedimento da psicoterapia que consiste basicamente em dividir o sonho em seus elementos (conteúdo manifesto) e procurar as ocorrências que se ligam a cada elemento (conteúdo latente).

Em seguida procura estabelecer qual processo psíquico é responsável pela transformação do conteúdo latente em manifesto (elaboração) e, finalmente, por que motivo isso aconteceu.

Pela relação entre os dois conteúdos Freud estabelece três categorias de sonhos:

1 .

Possuem sentido e são compreensíveis, podendo ser incluídos sem violência na vida psíquica do sonhante; o conteúdo manifesto coincide com o latente: não há elaboração;

\section{2.}

Possuem sentido e são compreensíveis, mas causam estranheza.

3.

Não possuem sentido e não são compreensíveis e causam estranheza.

Particularmente nos sonhos da $2^{a}$ a 3ạ categorias surgem enigmas que só 
desaparecem quando se substitui o conteúdo manifesto pelo latente.

Refazendo, ao inverso, o caminho da elaboração, o autor descobre passos reveladores que assim resumimos:

1 .

Cada um dos elementos do conteúdo manifesto é supradeterminado pelo material das idéias do sonho.

2.

Cada elemento do conteúdo manifesto está ligado a várias idéias latentes e uma única idéia é representada por mais de um elemento, através de cruzamentos e não por simples convergência. Disso decorre que a elaboração procedeu a uma Condensação.

Fenômenos que se explicam pela Condensação:

a) $\mathrm{O}$ acervo de idéias latentes que se reuniram para formar o conteúdo manifesto deve ser apropriado - para tanto precisa integrar vários elementos comuns a todos os componentes. Ora, se as idéias latentes não têm esses elementos comuns, a elaboração do sonho se encarrega de criá-los, aproveitando-se, por exemplo, do duplo sentido das palavras, como processo regular.

b) através da Condensação, a elaboração do sonho apresenta freqüentemente:

— um único elemento misto, no lugar de duas idéias contrárias;

- um indivíduo numa situação que foi de outro protagonista;

- a síntese de várias pessoas numa só;

- pessoas coletivas, mistas, produtos híbridos.

Conclusão - a decomposição de tais produtos, por meio de análise, conduz, com freqüência, pelo caminho mais curto, ao significado do sonho.

Durante a elaboração ocorre também uma transmutação de valores psíquicos ou um processo de deslocamento do sonho, ou seja, durante a elaboração do sonho, a intensidade psíquica desloca-se das idéias e representações às quais pertence justificadamente, para outras que não têm direito a tal acentuação.

Fenômenos que se explicam pelo Processo de Deslocamento:

a) Um elemento secundário, impreciso do sonho, constitui com freqüência o representante mais direto da idéia latente. Isso ocorre principalmente quando se trata de realizações muito disfarçadas do desejo.

Conclusão - Se conseguirmos acompanhar passo a passo o processo do deslocamento, chegaremos a adquirir dados que nos apontam os estímulos e as conexões dos sonhos com a vida desperta.

3.

Idéias visuais - $\mathrm{O}$ conteúdo do sonho não consta exclusivamente de situações, encerra também fragmentos de quadros visuais, pedaços de idéias não transformados.

Perda dos laços lógicos - as idéias latentes que nos revela a análise sã̃o uma complicada estrutura psíquica cujos componentes se acham nas mais diversas relações lógicas (condição, divagação, objeção etc.). Verificou-se terem-se perdido, na elaboração, os laços lógicos que mantinham unidos os materiais das idéias latentes e terem ficado, em seu lugar, as características formais que lhes são próprias. Ex.

- a aproximação no tempo e no espaço é reproduzida como em pintura: 
colocando juntos objetos que pertencem a tempos diferentes;

- a relação de causa e efeito é representada pela transformação direta de um objeto num outro ou pela sucessão imediata de pedaços diferentes de sonho;

- a relação de causa e efeito é representada pela transformação direta de um objeto num outro ou pela sucessão imediata de pedaços diferentes de sonho;

- a alternância não é expressa no sonho; os dois membros estão juntos e igualmente justificados (e não ou);

- as idéias contraditórias são expressas pelo mesmo (único) elemento ou por seu contrário;

- a analogia, a concidência é expresso pela sensação de não poder-se mover livremente;

- a analogia, a coincidência permanece, no sonho, como ponto de apoio para a criação de uma nova unidade;

- a contradição ou burla ou injúria são expressas pelo absurdo.

4 .

Ordenação enganadora. A elaboração atua a posteriori sobre o conteúdo do sonho já formado, na tentativa de que o sonho se torne compreensível. Esta ordenação situa o desconhecido lado a lado com o conhecido, para querer explicá-lo. Nesta fachada são empregadas com freqüência fantasias optativas que se encontram já formadas nas idéias latentes. São elas do mesmo gênero que as dos sonhos diurnos; repetições de cenas infantis ou nódulos deles misturados com outro material. Uma conclusão no sonho não passa de repetição de uma conclusão que teve lugar nas idéias latentes.

Vejamos agora como esses elementos podem ser aproveitados na análise do sonho do 'fatigado mortal', no capítulo sexto de Ka.

1.

Integração e criação, por parte da elaboração, de elementos comuns aos componentes do sonho, pelo aproveitamento, por exemplo, do duplo sentido das palavras.

Tal integração, no texto, observa-se claramente no tratamento ao qual são submetidas as palavras púgavitsa (botão - na tradução do capítulo entretanto, por razões de coerência interna, esta palavra foi transposta, para criar a correspondência em Português, de 'adusto' - 'susto' e 'assustador'. (Vide a tradução) e pugáiuchtchii. (assustador) Aqui é aproveitada a homofonia como veículo da integração semântica que o autor quer ver entre a palavra púgavitsa (botão) e a raiz pugát (assustar).

Um exemplo mais velado de integração de elementos comuns onde o veículo é o jogo de palavras encontra-se na frase:

"A queda das corujas, corujincidência estranha e enigmática, surpreendeu-me"

Onde padiénie sov (queda de corujas) brinca com sovpadiénie (coincidência traduzido por 'corujincidência').

2.

Apresentação pela elaboração de:

a) um único elemento misto, no lugar de duas idéias contrárias:

"velofinas pessoas" - elemento misto, híbrido, que remete ao ao mesmo tempo a um ser humano e a um animal.

b) pessoas coletivas — "rebanho". 
c) um indivíduo numa situação que foi de outro protagonista: "De minha mão pendia, enrolada com graça, uma pequena víbora doméstica."

(Já referimos, nas notas à tradução, que Nadiejda Nicoláieva possuia, na época em que o poeta a conheceu, uma serpente domesticada que se lhd enrolava no braço).

c) um indivíduo numa posição que desejaria fosse de outro protagonista:

"erva/pecadora" em "uma erva implorante, empoeirada, se me enroscava nas pernas e serpenteava pelo chão, pecadora que pedia misericórdia".

\section{3.}

Processo de deslocamento da intensidade psíquica que ocorre durante a elaboração: um elemento secundário, impreciso, do sonho, constitui com frequiência o representante mais direto da idéia latente, principalmente quando se trata de realizações muito disfarçadas do desejo:

"Eu a amava" - no sonho reproduzido no texto o sonhador refere-se à pequena víbora, enquanto que na vida real - sempre de acordo com as informações do crítico R. Duganov - Khlébnikov amava Nadiéjda.

4 .

O conteúdo do sonho encerra fragmentos de quadros visuais não transformados:

"Um macaco empalhado com espuma nos lábios negros de cera; a costura preta era claramente visível sobre o peito; nos braços, uma mulher de cera."

"No meio destas sarças de amora, no meio desses salgueiros, cobertos de raízes de ruivos cabelos espessos onde tudo era tranqüilo-nublado, austero-cinza, onde o beberrão solitário se agitava no ar e as árvores eram calmas e severas...

5.

Durante a elaboração há perda dos laços lógicos que mantinham unidos os materiais na realidade e sua substituição por características formais:

a) aproximação no tempo e no espaço, colocando juntos tempos e objetos:

"Voltava para casa... eu ia para casa".

No sonho de Khlébnikov tudo ocorre numa única unidade de tempo, entre os dois parênteses voltava para casa e eu ia para casa.

b) expressão de idéias contraditórias por um único elemento ou por seu contrário:

"Eu a amava" - referindo-se à víbora — pode significar "eu a odiava" — se nos for permitida a seguinte especulação:

A víbora era objeto do amor de Nadiéjda. Ela desviava, portanto, o amor que poderia ter sido dirigido ao poeta. Por isso ele a odiava .

c) a contradição é expressa pelo absurdo:

"No começo, água viva, depois, água morta".

Sabemos, pela nota à tradução, o que a frase significa. Com efeito, primeiro dar vida aos pedaços de um corpo para depois deixar que se juntem, é um absurdo que pode revelar tanto a insuperabilidade de certo conflito, quanto o desejo de destruir qualquer possibilidade de solução. 


\section{Notas}

1. Ka. Famoso conto-poema de Velimir Khlébnikov (1885 - 1921), considerado por R. Jakobson como o poeta mais original do século $\mathrm{XX}$. O conto foi traduzido do russo pela autora do presente estudo e foi revisto por Boris Schnaiderman e Haroldo de Campos. Quanto ao significado da palavra 'Ka', vide nota n' 4.

2. Cf. o artigo "A poesia contemporânea" escrito por Khlébnikov em 1919, uma parte do qual foi publicada na revista "Poétique" nọ 1 . (op. cit.).

3. Cf. A peça do poeta "Zanguesi", onde são explicados alguns traços simbólicos das letras. Cf. também as citações extraídas do "Livro de preceitos" particularmente as que se referem a Artistas do mundo (op. cit.).

4. De acordo com a mitologia egípcia, tão logo a alma, chamada Bha, passa para o reino do além, Ka permanece com a múmia. Ka é uma força vital misteriosa, uma réplica da alma, onde continua a viver um reflexo mágico da vida terrestre, no túmulo do falecido, ou nas reproduções deste túmulo. Imagens, estatuetas, miniaturas de utensílios tomam o lugar dos objetos reais. Operações mágicas lhes conferem eficácia e todas estas réplicas em miniaturas têm a capacidade de atrair Ka.

No decorrer dos séculos, os sentidos que se atribuiram a Ka variaram e se enriqueceram de novos valores. Tendo como homófono o touro, o nome Ka traria implícitos em si a força geradora, o vigor sexual e a força vital, suporte da vida física e espiritual.

Às vezes Ka confunde-se com a imagem de um espírito alado, e, particularmente, de um pássaro com traços humanos. Nas obras da própria cultura russa tal representação é bastante freqüente. Cf., como ilustração, a obra "A Concise History Of Russian Art" (op. cit.).

5. Cf. "Structure du Poème de Khliébnikov On me porte à dos d'elephant de V. Vs. Ivanov in Tel Quel - Paris, 1969 (n⿳⺈ 35).

6. Vide a tradução do capítulo anexa ao presente trabalho.

\section{Bibliografia}

Jakobson, R. - Lingüística. Poética. Cinema. Ed. Perspectiva, S. Paulo, 1970.

Khlébnikov, V. - Le Pieu du Futur, Ed. L'Age d'Homme, Paris, 1967.

Khlébnikov, V. - Sobranie Sotchinienii (Obras Reunidas), Ed. W. F. Verlag, München, 1968.

Pó́tiQue - nọs. 1, 4, 7. - Ed. Seuil, Paris, $1971-2-3$.

Talbot Rice, T. - A Concice History of Russian Art, Thames \& Hudson, N. York, 1963.

RACHeT, G. et M. - Dictionnaire de la civilization égyptienne, Ed. Laurousse, Paris, 1968.

Duganov, R. e Vs. V. Ivanov - Textos datilografados.

Freud, S. - Obras Completas - Vol. I. Editorial Biblioteca Nueva, Madrid, 1967. 